\title{
Research on Knowledge Assets Assessment Based on the Context of the Global Knowledge
}

\section{Management}

\author{
Jiansheng Tang \& Chenghong Li \\ School of Management, Tianjin University, Tianjin 300072, China \\ E-mail: tjs@tju.edu.cn
}

This paper is funded by Tianjin University self-oriented innovation fund.

\begin{abstract}
This article thinks that knowledge management includes knowledge learning and knowledge innovation, the value of knowledge in these two areas is produced, and after these two processes, have knowledge assets. In this paper, the ideas and methods of assessment about knowledge assets are proposed in the field of knowledge management, and analysis and research on these methods.

Keywords: Knowledge management, Knowledge assets, Assessment methods

In both the state and enterprises knowledge is an important resource, and has increasingly become important components of the core competitiveness. It is much more difficult to assess the knowledge of an enterprise than the value of a product or technology, because knowledge is not only reflected on the product or technical level, but also exists throughout the production and management process. Management of the types of knowledge that is used to develop enterprises is a very huge project. In a sense, the knowledge used in an enterprise production and management processes include almost all areas of knowledge, but some knowledge has become a necessary condition, has become a day-to-day business knowledge that is required by the development of the core Knowledge, of course, no other relevant knowledge can't absolutely go. In the area of enterprise knowledge management, in fact, that reaches on those knowledge which is in urgent need or innovative knowledge, this is an important foundation for the development of enterprises. Therefore, the knowledge of enterprise knowledge management has certain boundaries, in this context assessment of the knowledge assets is meaningful.
\end{abstract}

\section{The nature of knowledge assets under the conditions of knowledge management}

The research on the nature and value of the properties of knowledge earliest comes from the research on scientific knowledge, and formed a traditional evaluation of scientific knowledge, that is published by the outcome of the ways to realize its value, and stressed the public meaning of scientific knowledge, such as the first U.S. sociologist Merton stressed that creativity, competitiveness of scientific knowledge, can be repeated verification, universality, suspected to be critical, public and shared, and so on. In the traditional concept of knowledge, it seems that knowledge is not a commodity and its price which is only starting to buy books does not reflect the cost of the value of knowledge, including knowledge dissemination and use, Assessment the cost of using knowledge is of no significance. For example, users of knowledge who use the knowledge of publications do not pay the additional costs, as if every single personal use or do not have to pay the full knowledge and the knowledge of the production cost or value of decisions of the cost, but from scattered into many people come to share the responsibility to pay their labor; Even so, the cost of production of knowledge is not necessarily all be rewarded, we believe that such a statement appears to be untenable. This is because knowledge - knowledge of the publications is the significance of commodity prices, rather than a kind of public goods nature. In fact, some knowledge of atomic physics knowledge is given, for example, you use this knowledge to product atomic bombs, perhaps merely in order to increase knowledge, there is no practical application, but the knowledge for the users of these terms of expenditure is no difference, they use a commodity, have nothing special. In fact, you can purchase the same steel, you can allow manufacturers to create common ordinary farm tools of low prices; you can also enable well-known artists to process the exquisite works of art of high cost and as a result, their purchase price will not be much difference, May be affected by market price 
fluctuations. Therefore, some explicit knowledge have the prices, such as the knowledge of publications, which is priced in accordance with the book market price mechanism. As for the books do not sell good price, which is decided by the relationship between supply and demand of knowledge market, it is not related with the producers of knowledge.

The market mechanism is a way of social recognition, because the market itself is a voluntary mechanism, it can not be fully intervened by human. Knowledge market seems to refer to the concept of similar to Book Fair, or is market knowledge of a general sense, involving intellectual property rights, including copyrights, trademarks, patents, and so on. Based on the concept of goods of the economics, we give knowledge products such a definition: knowledge commodities is used to exchange of knowledge, and the value of knowledge commodity is copyright. And the number of books printed will be determined by the market. Therefore, knowledge-based economy that is not the price of knowledge, but knowledge of the value. And knowledge management and organizational learning theory of knowledge in the field of economics concept - a resource or the concept of intellectual capital is defined as the evaluation of the knowledge is given combined with products and services of companies. Therefore, we believe that knowledge management is concerned about the economic function of knowledge, how much interests can be given to the enterprises, stressed that the tools of knowledge, available, can be transformed, the economy and so on.

Based on the special nature of the area of knowledge management, we believe that knowledge of commodities and knowledge of the market is not the main target of our research, knowledge management is the first study on the subject of management meaningless. And knowledge management need to study the object is the knowledge found in organizations, that is, knowledge with the combination of people, that is, the knowledge in the course of use or "use knowledge." Some knowledge management experts focus on research on knowledge products and knowledge of market, this appears to have deviated from the knowledge management and organizational learning the subject. For example, Karl - Paul Fry in the book of "knowledge management" refer to the "knowledge products" and "knowledge market" concept, the concept of knowledge goods are publications significance of knowledge goods including Internet portals. Drucker think that knowledge management raises difficult questions to the economy, it seems that this problem does not exist. For example, Drucker believes that the fact lets economists and management experts face major problems: computing technology and business philosophy are much more difficult than statistical products, services and capital (Drucker, 1993).In fact, Drucker has a wrong understanding that he fabricates the concept of knowledge of commodities and market knowledge that do not exist, in fact, knowledge of commodities and the market has long existed and still exists, but there is no calculation Special difficulties. Or that he confused the concept of the knowledge management and knowledge of goods, knowledge management is a management major in management people who have the knowledge, followed by the explicit knowledge. So, research on personal knowledge and organizational knowledge and learning is the key issue, but the problem is not economics, but management problems. Therefore, we believe that knowledge management and organizational learning is not on knowledge of the attributes of goods, but on knowledge-proliferation in the process of the production of knowledge and new knowledge production process, that is, as on the production process, the needs to research on Learning and innovation activities of the people and organizations with the production process.

\section{The different manifestations of Knowledge assets}

In the framework of the concept of intellectual property rights, the method used to define knowledge of the commodity value can not define tacit knowledge, knowledge dissemination and use of knowledge of the attributes of goods. It appears that the price of knowledge management knowledge still has other pricing principles, and this principle must be established with the attributes of the community on the basis of the inherent laws. At present, in the field of knowledge management, knowledge assets on the assessment method is to use knowledge assets and human resources, capital and organizations, such as customer relationship capital to analysis and research, specifically including several in the following points:

1) Knowledge assets and investment relations

Knowledge assets is a complex system that can not be fully included concept of goods, despite this, but if knowledge assets is not linked to the value, price, profits, then for the enterprise knowledge management, it is meaningless to discuss. Therefore, this paper thinks that knowledge assets refers to sum of knowledge required in the process of the production and management. the core prices of knowledge assets is said by the knowledge, the price of technology or the profits.In fact, from the perspective of knowledge management, the value of organizational knowledge can be summed up as the ability to generate profits or increase the capacity of total assets. Reinsch Hart, who summed up as follows several measures: "A method of measuring knowledge assets is 
the $\mathrm{Q}$ ratio of TOBIN. Q ratio will be the market value of a property with the alternative (book value) for comparison. This rate is often used to express their knowledge content. "The second method is "knowledge asset value-added potential measurement methods...... assets in accordance with the value-added and knowledge for human capital ratio of the total expenditure calculated." The third method is: "Knowledge assets accounting methods...... In the financial income and expenditure account, add a 'table of future investment', aims for the future three to five years, expenditures for intangible assets of the buffer "(Lai Reinhart, 2001,618). These measurement methods about the knowledge assets or the value of organizational knowledge often pay more attention to the details of the calculation. The management method of measurement is the significance of the strategic development and successful implementation of the strategy, new technology development and its application to business success, the new management concepts and culture and the establishment of well-functioning management and team-building and the success of performance, coupled with the Financial indicators and non-financial indicators of a comprehensive evaluation. For example, Ross design of the model of the knowledge assets of the measurement methods, "it is the starting point under the management of high-level business strategy and key success factors. Coupled with the many financial and non-financial indicators, this created the link between operational model (business processes) and Long-term goals (strategic) "(Lai Reinhart, 2001,619).From the perspective of enterprise development strategy, the study of intellectual property is very significant, because this perspective started to pay attention to the use of key business areas of knowledge, and enterprise development.

This perspective has a very deep understanding of the nature of knowledge assets. Because, knowledge management discuss importantly the issue of growth in organizations knowledge, in this sense, knowledge assets of an enterprise can not all of the knowledge assets that can be a part. Therefore, we believe that in the process of enterprise knowledge management, knowledge assets is all tangible and intangible assets or all of the costs used to access to knowledge and innovation, or means of all of the investment in knowledge learning and innovation. as a result, knowledge assets was viewed as expenses of use in enterprises which have the purpose or plan to study and creation of knowledge, or under the guidance of the corporate strategy structural arrangements or re-organize the orderly knowledge and the knowledge of the activities System, and demonstrated the production capacity of knowledge and eventually converted to the enterprise value of products and services. At the same time, what needs to be emphasized is not just these products and services of value, but also the management capacity and the ability of future deliverables of the actual process.

2) Human capital and knowledge assets

Generally, human capital or intellectual capital is on behalf of the expected time in the future or to provide products and services.

1964, Becker human defined capital as: "Human capital development is usually can be interpreted as, have a part in the monetary and spiritual aspects of the revenue by increasing human resources." Economic Cooperation and Development Organization define it as: "human capital could be interpreted as knowledge for the production of goods, services from the personal life and in the market and non-market environment" (quoted by Lai to Hart, 2001,619).This article is the meaning of human capital is the product of integration of the people's knowledge and social, mainly refers to a person gets social identity because of knowledge and technology, capacity and access to certain social competence or professional work, or is a person in certain position needs the competence of knowledge, skills and its logo. In the process of organizational learning and innovation, human capital is expected to get the knowledge and ability to learn the eligibility of participating organizations, and the investment access to knowledge and improve the ability in the process. Therefore, the meaning of human capital includes: prestige in the organization, charismatic, interpersonal networks, sense of innovation and cooperation awareness, problem-solving abilities, the implementation of the mandate or ability to fulfill its mandate, and these capabilities are got through self-study and organizations receive training in the learning activities. Therefore, human capital is a person's experience or experience (including education), practical work experience, including the successful history. In the organizational learning process, a person's sense of innovation ,the spirit of cooperation and sense of character often have a more important position. And not only cost issues, such as wages, training, honor and respect; including good spirit in a good cultural environment, knowledge and intelligence, character, such as the comprehensive development of its core is the self-knowledge-sharing Management capacity.

3) Venture capital and knowledge assets

A corporate capital is determined by its products or services, including brand value, reputation, technology, culture, management, and many other elements of the complex, which is a certain capacity of production 
knowledge. Tuo Meier believes that the capital is "a human capital, its properties included in the enterprise organizational relations. special member of enterprise, or in the knowledge base of enterprises " (Tuo Meier, 1987, 1998).Reinsch Hart said: "As the capital included the concept of corporate bodies and behavior variables, it can also be seen as an extension of human capital" (Lai Reinhart, 2001, 622). These views have a certain reasonable, because people are carriers of knowledge, organizational knowledge forms organizational capital through personal knowledge of the coordination mechanism, and that is, the capital. Based on the ability of enterprises to use knowledge of performance, therefore, we believe that in the corporate capital the factors of management play a role in its production or the key.

Therefore, we believe that the management of organizational learning and innovation management capacity is the most important capacity. This capacity includes the ability to share information and knowledge, learn together and solve problems, communication and exchange of cooperation. Therefore, from a knowledge management perspective, we think that corporate capital is the capacity of setting of knowledge capital, its elements include: the culture capacity of learning and innovation of enterprise (to encourage new ideas, allow the existence of different points of view, the various new ideas and new knowledge of learning Enthusiasm, etc.); Formal and informal learning and innovative model of organization and the way establishing contact with the outside world; the quality of human capital of organizations (professional competence, ability to cooperate, social interaction patterns, etc.); Dealing with internal and external information and knowledge accumulation of information and knowledge ability, organizational regulate system (written rules and unwritten rules) is a knowledge assets of the major constraints; Internal knowledge resources integration mechanism of enterprise (exchange and communication, discussion of the condition and operation mode) and the innovation mechanism, through a variety of learning to realize the increasing value of the knowledge assets.

4) Social capital and knowledge assets

Social capital is a sociological concept now which has been introduced into the management field. Existing in the literature that social capital is to organize credit, a collection of guidelines for action, social network or a comprehensive view of these. From knowledge-based management perspective, we believe that social capital has certain attributes of knowledge assets that can generate additional revenue of knowledge for enterprises. The additional yield is on the premise that the enterprise's credibility and ability to participate in the community, the most important thing is for the benefit for collaborators.

Social capital can create opportunity of information and knowledge-sharing, therefore, social capital is an important corporate knowledge assets component. Through social capital it can create a good social network, in this network we can get a lot of valuable information and knowledge, rather than through access to commodities trading.

At the same time, it will have an important impact on corporate strategy, production technology and management. According to the business links and knowledge management process, we believe that social capital is the external resources the organization can use, including the corporate and personal resources of organization, the social relations of the public credit of organization and the social responsibility of organization, and so on. For example, the process of knowledge acquisition of enterprises have a process of an information and knowledge introduction from outside, and the external environment (social, economic and cultural factors) decided to learn or acquire the means. Therefore, an organization in the social structure mainly is the location in the competitive landscape, including the relationship between business and customers or consumers, suppliers, market management departments, universities, research institutions, government, the relationship has a direct impact on access to knowledge enterprises and innovation capability.

In short, the knowledge assets is a composite of the concept, is related to investment of the knowledge management business, also is closely related to human capital and enterprises, venture capital and social capital. Therefore, assessment of the knowledge assets of an enterprise is not confined only to enterprises of profiling the scope of knowledge, including the various channels of access of knowledge and a source of innovation , and within enterprise the adjustment or consolidation of the structure and transform into the ability of the knowledge innovation of enterprises, which means that the ability which makes enterprises produce new products or services, and ultimately become a key factor of core competitiveness of enterprises.

\section{Knowledge assets and assessment method}

In all kinds of literature on knowledge management, many scholars have the definition of assessment methods and research of the knowledge assets. Weiss said: the value of the knowledge assets of an enterprise should be calculated in accordance with the difference between the market value and its book value (Weiss 1997; Stewart, 1997; Ross, 1997; Reinsch Hart, 2001, 616). Ross divided knowledge assets into human capital and structure 
capital (Ross, 1997).Ed Vincent and Malone divided it into human capital, organizational capital and customer capital (Ed Vincent and Malone, 1997; Reinsch Hart, 2001,617). These views from different angles inspected the problem of the knowledge assets assessment, but it has not yet reached a perfect level. Therefore, this paper think that, based on knowledge management practice, to assess their knowledge assets to the combined the actual process of inspection of enterprise knowledge acquisition and innovation. This is because the new value of knowledge assets is produced in these two areas, and eventually formed a corporate knowledge assets total. Based on the study of knowledge management, the paper defined the various factors or perspective of the knowledge assets as follows:

1). Human capital is the sum of the personal knowledge and learning ability, this sum can be divided into access to knowledge and application of knowledge and innovation process, and through its manifestations of the operational capacity. It also includes personal character traits and the quality of innovation, quality of the spirit of moral quality.

2). The enterprise capital refers to the level of knowledge management or organizational learning, namely the capacity of the establishment of an effective team and the knowledge innovation - into understanding with fermentation capacity. The most important organization capital is capital management and knowledge management technologies, including the corporate culture, knowledge infrastructure, knowledge and technology, databases, etc.

3). Social capital refers to the information and knowledge of the customer's understanding of the system, and on the basis of information and knowledge, and to create the good relations of cooperation and to maintain this relationship, and so on. achieve the interaction of human capital, organizational capital and social capital is through organizational learning and innovation process .If not through this process, they can not be reached among the best. Therefore, in the aspect of knowledge management, knowledge assets plays an important role, that is the process of changing static knowledge into a dynamic knowledge, this process is a proliferation process of the enterprise value. Their relationship is showed in Figure 1.

In ideal circumstances, the individual of the enterprises in organizational learning - the process of innovation, personal knowledge is activated, and in organizational environment have the opportunity to communicate with other people, communication and collision - is the interactive process can trigger the "knowledge fermentation", as a result personal knowledge into the organizational knowledge or personal knowledge to rapidly improve the increasing value of human capital. Organizations capital after this process, was tested, amended and improved, and ultimately improve overall capacity of the Organization. This process of the use of social capital includes two aspects: First, after learning - innovation process it can deepen the understanding of customers and to enhance the significance of understanding; Second, after learning - innovation process we can find new customers, the organization makes effective use of networks, namely mobilizing the enthusiasm of the individual.

In addition, the study - innovation process will also be the process of being collaborative corporate goals and objectives of knowledge, the key core of this process is taking scattered individual learning, personal knowledge and organizational learning, organizational knowledge into a coordinated or integrated one, the results of this process is learning - innovation. The meaning of collaborative is using the mechanism of corporate culture and encourage as the order parameter, and to reach a certain threshold, to let the organization achieve a new orderly state. In fact, the coordination mechanism can play a role on the basis of the study - innovation the specific relationship is showed in Figure 2.

Coordination mechanism is included in the study - innovation process, and it can play its role only when incentive mechanisms play a role in this process, the main incentive mechanism is to stimulate the process of the learning - innovation and effectiveness. About the actual process of corporate strategy development and new technology development, there are a large number of the example about group work and the team -- these facts all can prove that the above-mentioned framework.

From the above analysis we can see that the corporate knowledge assets assessment is mainly based on knowledge innovation, that is, knowledge innovation is achieved by increasing the value of in human capital, organizational capital and social capital of enterprises. When direct assessment of corporate knowledge assets, namely the assessment of knowledge itself has difficulties, you can use a more simple way, by assessing the ability of innovation knowledge of enterprises. This approach is not only simple, but also fully in line with corporate knowledge management objectives and values. 


\section{References}

Baen Si. (2004). Knowledge management systems. Machinery Press.

Dierkesi. (2001). Organizational learning and knowledge innovation. The Shanghai People's Publishing House. 615-630

Drucker. (2002). Innovation and entrepreneurial spirit. The Shanghai People's Publishing Press.

Frappaolo. (2004). Knowledge management. The Huaxia Publishing House.

Ke Mali. (2004). Effective knowledge management. The Chinese Business Joint Press.

Maiye Si. (1998). Knowledge management and organizational design. Zhuhai Press.

Matheson. (2003). Learning organization research and development team management and guidance of Machinery. Industry Press,

Xi Dan. (2003). Man of Prevlaka, intelligent. Shanghai Jiaotong University Press.

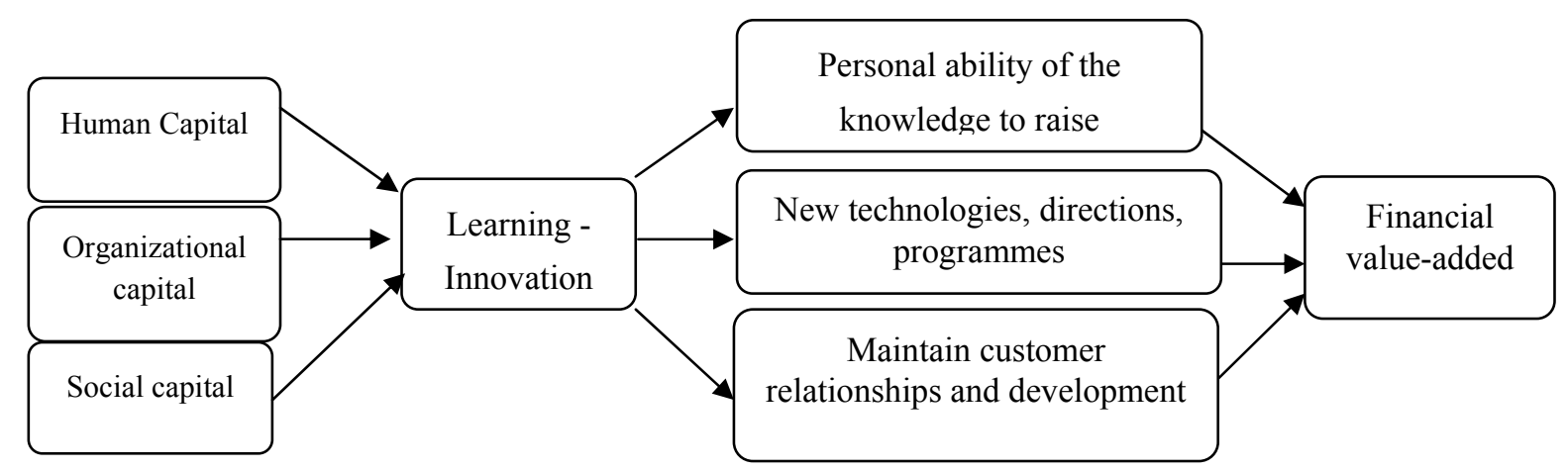

Figure 1. Proliferation process of the enterprise value

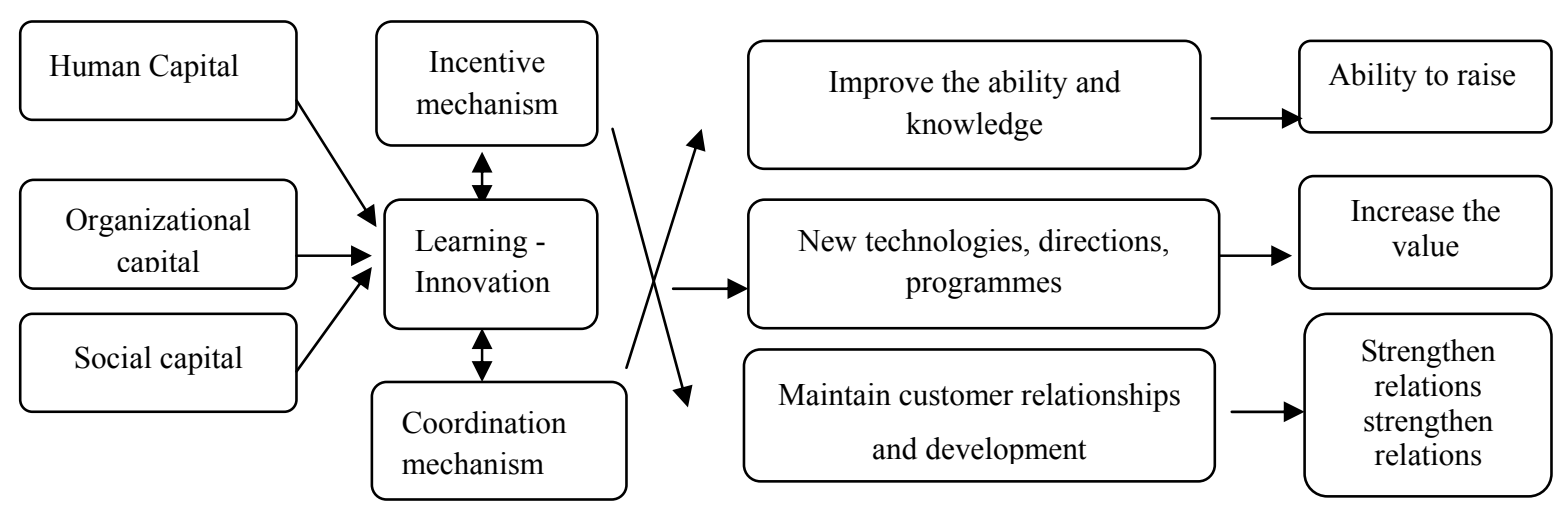

Figure 2. Coordination mechanism 